\title{
Principal climatic and edaphic determinants of Culicoides biting midge abundance during the 2007-2008 bluetongue epidemic in the Netherlands, based on OVI light trap data
}

\author{
F. SCOLAMACCH I A ${ }^{1,2}$, J. VAN DEN B R O E K ${ }^{1}$, R. MEISW INKE L ${ }^{2,3}$, \\ J. A. P. HE E S T E R B E E K ${ }^{1}$ and A. R. W. E L B E R S ${ }^{2}$ \\ ${ }^{1}$ Department of Farm Animal Health, Faculty of Veterinary Medicine, Utrecht University, Utrecht, the Netherlands, ${ }^{2}$ Department \\ of Epidemiology, Crisis Organization and Diagnostics, Central Veterinary Institute of Wageningen University, Lelystad, the \\ Netherlands and ${ }^{3}$ Netherlands Food and Consumer Product Safety Authority, Utrecht, the Netherlands
}

\begin{abstract}
Palaearctic Culicoides midges (Diptera: Ceratopogonidae) represent a vital link in the northward advance of certain arboviral pathogens of livestock such as that caused by bluetongue virus. The effects of relevant ecological factors on weekly Culicoides vector abundances during the bluetongue virus serotype 8 epidemics in the Netherlands in 2007 and 2008 were quantified within a hurdle modelling framework. The relative role of meteorological parameters showed a broadly consistent association across species, with larger catches linked to temperature-related variables and lower wind speed. Moreover, vector abundance was found to be influenced by edaphic factors, likely related to species-specific breeding habitat preferences that differed markedly amongst some species. This is the first study on Culicoides vector species in the Netherlands identified during an entomological surveillance programme, in which an attempt is made to pinpoint the factors that influence midge abundance levels. In addition to providing key inputs into risk-mitigating tools for midge-borne pathogens and disease transmission models, the adoption of methods that explicitly address certain features of abundance datasets (frequent zero-count observations and over-dispersion) helped enhance the robustness of the ecological analysis.
\end{abstract}

Key words. Culicoides surveillance, bluetongue, climate, count data, hurdle regression, soil, vector, the Netherlands.

\section{Introduction}

Culicoides biting midges are true biological vectors of viruses that cause devastating diseases in domestic and wild ungulates worldwide. These include bluetongue (BT), African horse sickness (AHS) and epizootic haemorrhagic disease (EHD) (Mellor et al., 2000). Within European ecological biomes, as defined by Olson et al. (2001), various Culicoides species are proven or incriminated bluetongue virus (BTV) vectors.
In the Mediterranean zone, these comprise the traditional African-Asian vector, Culicoides imicola (Kieffer), and the indigenous Palaearctic species Culicoides obsoletus (Meigen), Culicoides scoticus (Downes and Kettle) and Culicoides pulicaris (Linnaeus) (Caracappa et al., 2003; De Liberato et al., 2005; Savini et al., 2005). Moving further north into the temperate zone, in which C. imicola has never been reported, two additional resident species, namely Culicoides dewulfi (Goetghebuer) and Culicoides chiopterus (Meigen), act as 
novel potential vectors for BTV (Meiswinkel et al., 2007; Dijkstra et al., 2008).

Climatic and other environmental factors are known to modulate the lifecycle of Culicoides species and have been linked to the timing and distribution of bluetongue outbreaks at a range of scales (Purse et al., 2008). Furthermore, the general assumption that bioclimatic data are surrogates for Culicoides geographical distribution and temporal abundance has been widely adopted to complement survey data. This has led to the development of climate-based models predicting vector distribution in unsurveyed locations and identifying areas at risk for bluetongue outbreaks (Baylis et al., 2001; Wittman et al., 2001; Tatem et al., 2003; Purse et al., 2004a). Despite their general relevance, because these models are usually implemented with Culicoides data obtained from within a single confined area, they have not proved accurate when applied elsewhere (Calistri et al., 2003; Capela et al., 2003). Further, in regions in which comparative mapping has revealed the geographic ranges of certain vector Culicoides species to be markedly disjunctive, this has been shown to be dictated less by climate and more by edaphic factors, especially terrain slope and soil type. Thus, in an irregular topography, for example, C. imicola is likely to be almost entirely absent from locations in which the terrain slope and soil texture induce water run-off and the rapid desiccation of the soil's surface layer because moisture is critical for the larvae of this species to survive and complete their developmental cycle (Conte et al., 2007). This caveat has driven later studies and shown that areas suitable for a given species are very specific to the particular landscape being inventoried, which gives greater explanatory power to models that incorporate a combination of ground-measured and remotely sensed climatic variables, edaphic, topographical and host availability factors (Calvete et al., 2009; Purse et al., 2012; Silbermayr et al., 2011).

Separate incursions by multiple serotypes of BTV into Europe have characterized the past decade (MacLachlan, 2010). These include a major epidemic involving a subSaharan strain of BTV serotype 8 that was reported first in the Netherlands in the second half of 2006 and spread rapidly to involve extensive portions of Europe that had not previously experienced the disease (Elbers et al., 2008). Although bluetongue is transient in a large part of northwest Europe, the probability of recurrence, along with the possibility of incursions by other midge-borne pathogens, remains poorly understood (Backer \& Nodelijk, 2011; de Koeijer et al., 2011).

Gauging the influence of ecological correlates on phenological patterns in Palaearctic Culicoides has been the subject of a number of recent studies (De Liberato et al., 2010; Purse et al., 2012; Sanders etal., 2011). With respect to the Netherlands, this knowledge is rudimentary at best and derives mainly from a single-point single-night sampling programme (Meiswinkel et al., 2008) and studies conducted at sub-national level (Takken et al., 2008). Hence, predictive modelling is still fraught with uncertainty (Hartemink et al., 2009). To refine and support risk management tools, such modelling must reflect the diversity of the Culicoides population around livestock, as captured by the national entomological surveillance programme. Such models, particularly for newly invaded regions, require knowledge of the wide array of midge-borne pathogens that can be spread by competent vectors, as well as a clearer understanding of the factors that drive Culicoides vector distribution and abundance.

The aims of the present study were: (a) to describe and quantify the influence of environmental features on weekly abundance of Culicoides vector species across the Netherlands; (b) to assess possible underlying ecological differences among vector species, and (c) to implement a statistical model for the study of Culicoides spp. surveillance abundance data.

\section{Materials and methods}

The surveillance dataset was combined with freely available climatic data, host availability information and edaphic characteristics that have been found to be effective predictors of the distribution and abundance of different Culicoides species (Baylis et al., 1998; Purse et al., 2004b; Conte et al., 2007; Calvete et al., 2009).

\section{Entomological data}

Entomological surveillance was established in the Netherlands after the first bluetongue epidemic, according to European Regulation No. 1266/2007. Accordingly, the country was divided into geographical units of about $2000 \mathrm{~km}^{2}$, which resulted in 21 compartments in which surveillance and monitoring activities were carried out (van Schaik et al., 2008). One farm per compartment was designated for entomological surveillance (Fig. 1); farms were selected from the 106 sampled nationally during the 2006 snapshot survey (Meiswinkel et al., 2008). In 2007 all 21 farms were monitored on a yearround basis with a standard weekly Onderstepoort Veterinary Institute (OVI)-type blacklight trapping protocol (Goffredo \& Meiswinkel, 2004), but in 2008 this number dropped to 11 in order to lower costs. Light trap records considered in the present study include weekly samples collected from January 2007 to December 2008. Taking into account trap failures and interrupted sampling at some sites, a total of 1541 collections were made (i.e. 990 of a potential 1092 in 2007 and 551 of a potential 572 in 2008). Weekly counts of biting midges were separately recorded for each of the species identified and sorted by sex; females were classified according to their physiological status, as described in detail in Meiswinkel et al. (2013).

\section{Climatic data}

Ground-measured climatic data were provided by the Royal Dutch Meteorological Institute [Koninklijk Nederlands Meteorologisch Instituut (KNMI) (http://www.knmi.nl/ klimatologie/)] as recorded from 36 weather stations located across the Netherlands. All meteorological stations were georeferenced so that the nearest station to each trap site could always be identified [multiple Euclidean distance calculation (http://www.edenextdata.com)]. The local topography for each selected weather station (elevation, slope and other topographic 


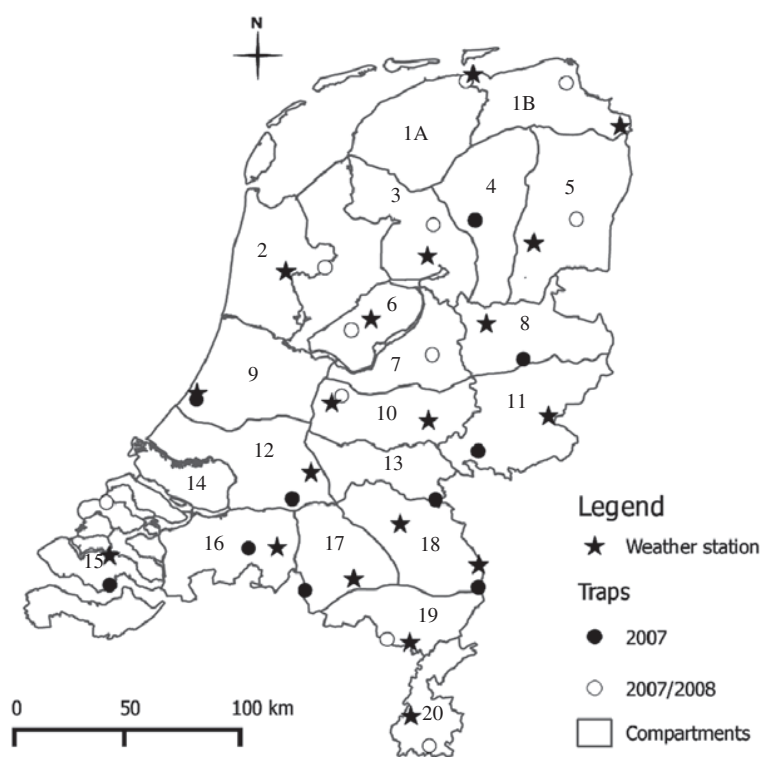

Fig. 1. Map showing the location of the 21 trap sites (one per compartment) and weather stations.

aspects, available from the KNMI website for each location), was comparable with that of the corresponding light trap location. Altitude, although always consistent between the two matched locations, is not a factor of great influence in the Netherlands, which has very little elevation difference and gently slopes from the southeast ( $322 \mathrm{~m}$ above sea level) to the northwest $(6 \mathrm{~m}$ below sea level); the majority of the country has a more or less flat topography. The terrain between each site sampled and the nearest weather station was not complex and included neither forest nor urban areas; therefore the wind speed measured can be assumed to be a reasonable approximation. For each of the selected stations, weekly means were calculated for the following meteorological variables collected daily: the minimum, maximum and mean temperature $\left({ }^{\circ} \mathrm{C}\right)$, relative humidity $(\mathrm{RH})(\%)$, air pressure $(\mathrm{hPa})$, amount of precipitation $(\mathrm{mm})$, and the evapotranspiration (Makkink, \%). For wind speed $(\mathrm{m} / \mathrm{s})$, we considered the hourly mean on the catch date, as Culicoides flight activity, as captured by OVI light trap, is assumed to be greatly diminished by higher wind speed on a daily basis. The values obtained were attributed to each trap record based on the catch date.

Remotely sensed imagery was used to derive three variables of environmental significance: the normalized difference vegetation index (NDVI); the daytime Land Surface Temperature (dLST), and the night-time LST (nLST). The NDVI is a common measure of plant growth and photosynthetic activity, which has been shown to correlate with soil moisture, rainfall and vegetation biomass (Campbell, 1996; Huete et al., 2002). The LST is a general index of the Earth's temperature in a particular location, whether the surface comprises soil or vegetation (Goetz et al., 2000). The correspondence between daily LST and in situ measurement data is accurate within $1{ }^{\circ} \mathrm{C}$ in the range from $-10^{\circ} \mathrm{C}$ to $50^{\circ} \mathrm{C}$, making the LST a widely used variable (Wan et al., 2002).
The NDVI, dLST and nLST data for 2007 and 2008 were obtained from the Avia-geoExplorer composite dataset (AviaGIS, 2010). This software allows for the generation of time series of the Moderate-Resolution Imaging Spectroradiometer (MODIS) satellite images and the attribution of indices to positions specified by the user. Available with a spatial resolution of $1 \mathrm{~km}$, the NDVI and LST images had temporal resolutions of, respectively, 16 days and 8 days. NDVI, dLST and nLST time series were derived for the 21 trap sites and the weekly mean values attributed to each record in the surveillance dataset.

\section{Soil texture data}

Edaphic properties are considered to have important influences on Culicoides population sizes because they are a measure of breeding habitat availability (Braverman et al., 1974; Conte et al., 2007; Titeux et al., 2009; Foxi \& Delrio, 2010). For each trap site, the Harmonized World Soil Database (HWSD) Viewer Version 1.1, a simple geographical tool to query and visualize a soil information layer to local scale, was used to obtain the percentages of sand, silt, clay and organic carbon in topsoil $(0-30 \mathrm{~cm})$ (FAO/IIASA/ISRIC/ISSCAS/JRC, 2009) (Table 1). The HWSD comprises 30-arcsecond (or $\sim 1 \mathrm{~km}$ ) raster images linked via the pixel value to the soil information system.

\section{Host availability data}

The presence of hosts is a prerequisite for the survival of blood-feeding Culicoides. Vector species abundance has been found either to be linked to land use (pastoral), host type and host density (Purse et al., 2012; Sanders etal., 2011), or to be not affected by the number and type of farmed animals (De Liberato et al., 2010). When host availability data were included as predictors, these data increased the variance explained by the predictive models, but the strength of the association with midge abundance or distribution was considerably lower than that of bioclimatic variables (Calvete et al., 2009; Purse et al., 2012). It very often happens that a high amount of variation in Culicoides abundance can only be explained by the combined effect of two (or more) factors as a result of their complex interactions and relationships with species-specific biological traits (Acevedo et al., 2010).

To explore the role of host availability on Culicoides weekly abundances, the number of cattle per compartment (van Schaik et al., 2008), and the numbers of cattle, sheep and goats kept at each trap site were included in the analysis (Table 1).

\section{Statistical analysis}

To obtain the best estimate for potential population size, studies of Culicoides population abundance and distribution have relied largely upon different averaging or 'maximum level' measures derived from trap catch data during the peak season of midge activity (Baylis et al., 1997; Conte et al., 
Table 1. Summary of host availability and soil texture features of the 21 sites sampled (one for each compartment) during the national surveillance programme.

\begin{tabular}{|c|c|c|c|c|c|c|c|c|}
\hline \multirow[b]{3}{*}{ Compartment } & \multicolumn{4}{|l|}{ Hosts } & & & & \\
\hline & \multirow{2}{*}{$\frac{\text { Compartment }}{\text { Cattle, } n}$} & \multicolumn{3}{|l|}{ Farm } & \multicolumn{4}{|c|}{ Topsoil $(0-30 \mathrm{~cm})$ texture } \\
\hline & & Cattle, $n$ & Goats, $n$ & Sheep, $n$ & Organic carbon, $\%$ & Silt, \% & Sand, \% & Clay, \% \\
\hline Farm 1A & $300000-400000$ & 237 & 0 & 0 & $<0.6$ & $>40$ & $21-50$ & $11-25$ \\
\hline Farm 1B & $300000-400000$ & 79 & 5 & 32 & $<0.6$ & $>40$ & $21-50$ & $11-25$ \\
\hline Farm 2 & $75000-150000$ & 59 & 0 & 0 & $1.2-2.0$ & $26-40$ & $21-50$ & $11-25$ \\
\hline Farm 3 & $150000-225000$ & 130 & 5 & 113 & $>2$ & $26-40$ & $<20$ & $26-40$ \\
\hline Farm 4 & $225000-300000$ & 79 & 0 & 68 & $1.2-2.0$ & $<10$ & $>80$ & $<10$ \\
\hline Farm 5 & $225000-300000$ & 101 & 0 & 0 & $1.2-2.0$ & $<10$ & $>80$ & $<10$ \\
\hline Farm 6 & $0-75000$ & 156 & 0 & 0 & $<0.6$ & $>40$ & $21-50$ & $11-25$ \\
\hline Farm 7 & $300000-400000$ & 111 & 7 & 0 & $1.2-2.0$ & $<10$ & $>80$ & $<10$ \\
\hline Farm 8 & $300000-400000$ & 89 & 0 & 0 & $1.2-2.0$ & $<10$ & $>80$ & $<10$ \\
\hline Farm 9 & $75000-150000$ & 280 & 0 & 53 & $<0.6$ & $11-25$ & $51-80$ & $<10$ \\
\hline Farm 10 & $300000-400000$ & 68 & 0 & 0 & $1.2-2.0$ & $<10$ & $>80$ & $<10$ \\
\hline Farm 11 & $300000-400000$ & 435 & 0 & 0 & $1.2-2.0$ & $<10$ & $>80$ & $<10$ \\
\hline Farm 12 & $150000-225000$ & 165 & 0 & 5 & $>2$ & $26-40$ & $21-50$ & $26-40$ \\
\hline Farm 13 & $75000-150000$ & 140 & 0 & 0 & $<0.6$ & $26-40$ & $21-50$ & $11-25$ \\
\hline Farm 14 & $0-75000$ & 86 & 0 & 0 & $0.6-1.2$ & $26-40$ & $<20$ & $>40$ \\
\hline Farm 15 & $0-75000$ & 130 & 0 & 0 & $0.6-1.2$ & $26-40$ & $<20$ & $>40$ \\
\hline Farm 16 & $150000-225000$ & 109 & 0 & 0 & $1.2-2.0$ & $<10$ & $>80$ & $<10$ \\
\hline Farm 17 & $75000-150000$ & 170 & 0 & 0 & $1.2-2.0$ & $<10$ & $>80$ & $<10$ \\
\hline Farm 18 & $300000-400000$ & 277 & 0 & 0 & $0.6-1.2$ & $26-40$ & $21-50$ & $11-25$ \\
\hline Farm 19 & $75000-150000$ & 118 & 0 & 0 & $1.2-2.0$ & $<10$ & $>80$ & $<10$ \\
\hline Farm 20 & $0-75000$ & 113 & 0 & 0 & $0.6-1.2$ & $26-40$ & $21-50$ & $11-25$ \\
\hline
\end{tabular}

2007; Purse et al., 2012; Rigot et al., 2012a). By contrast, in order to avoid the loss of information (i.e. varying activity rate and seasonality), we modelled the actual counts per trap catch.

Culicoides abundance datasets, such as those obtained yearround by the surveillance systems implemented in Europe, show a number of particular features: (a) large variations in catch size over a relatively short period of time (e.g. from week to week), sometimes of several orders of magnitude, and possibly reflecting changes in population size, the activity rate of parous midge females (proportion of host-seeking females that are active on a given night), or adverse weather conditions (Birley \& Boorman, 1982; Baylis et al., 1997); (b) frequent zero-count observations (negative catch records) reflecting the high degree of seasonality in midge activity in the north temperate zone (suppressed during the winter), and (c) dependency between observations caused by a longitudinal study design (repeated measurements on a weekly basis at the same trap sites).

When applied to such datasets, classical Poisson regression to model count data and its extensions (quasi-Poisson and negative binomial) may be of limited use because it may not yield a good fit for the distribution of counts that exhibit both over-dispersion and excess zeroes (Zuur et al., 2009). Other studies have shown the utility of applying to Culicoides data models that address features like frequent zero-count observations and over-dispersion (Carpenter et al., 2008; Viennet et al., 2011). The abundance data were heavily right skewed, with a variance: mean ratio ranging between 34 and $>100$, depending on the species, and contained a large proportion of zero counts (40-95\%). Box and whisker plots illustrate the weekly abundance and variability of each vector species across the country (Fig. 2A-J). Consequently, we used a negative binomial cloglog hurdle model (Cameron $\&$ Trivedi, 1998) to explore the relative effects of climatic, edaphic and host availability factors on year-round fluctuations in adult biting midge populations across the Netherlands, while addressing dataset-specific issues. An exploratory analysis by means of contingency tables of Culicoides species per week, stratified by year and location, revealed that zero counts were restricted to certain seasons, typically late autumn, winter and early spring. The only exception applied to C.pulicaris sensu stricto (s.s.), which was equally abundant across all 21 compartments, with little variability between sites and constant absence in compartments $1 \mathrm{~A}$ and 2 .

The two components of the hurdle model allowed us to investigate whether different factors are responsible for an event (i.e. the presence of Culicoides in the light trap) and for the strength of this event (i.e. size of weekly counts). The model feature described above proved to be useful and ecologically sensible because, for the majority of proven or suspected BTV vectors, the presence or absence of midges in the current study appeared to be unrelated to whether or not some locations were outside a species' range or niche, but, by contrast, more likely associated with their strong seasonality. At certain times of the year, sampling resulted in zero catches everywhere. After the spring flush, all the sampled sites were positive for the species considered, although abundances differed among weeks and among farms. As a consequence of the pattern observed, the model was fit to identify the driving factors that led to the commencement of the adult 

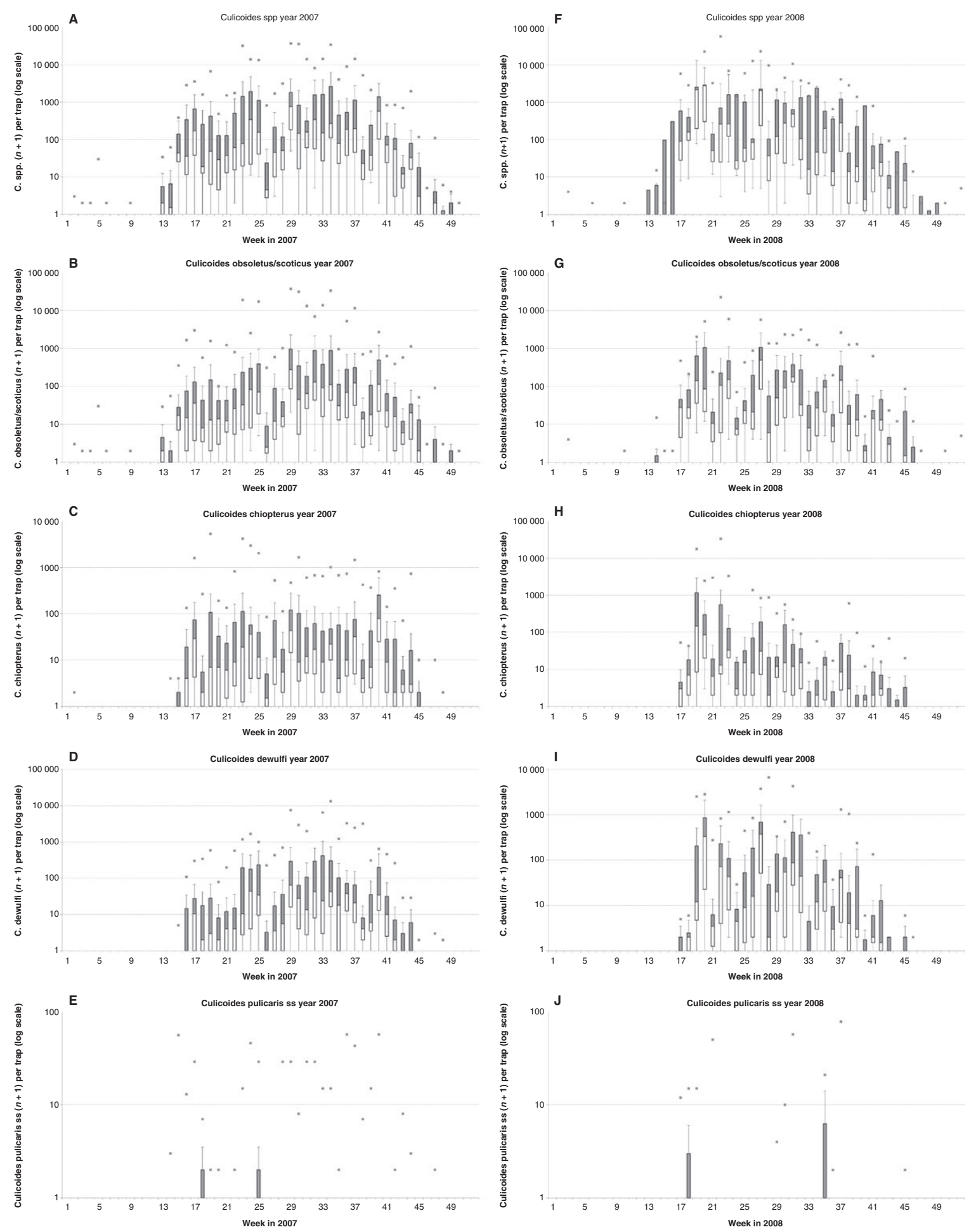

Fig. 2. Box and whisker plots of weekly abundances $(n+1)$ plotted on a log-scale of Culicoides spp. [(A, F) 40 species] and of five proven or potential bluetongue vectors $[(\mathrm{B}, \mathrm{G})$ Culicoides obsoletus and Culicoides scoticus, (C, H) Culicoides chiopterus, (D, I) Culicoides dewulfi and (E, J) Culicoides pulicaris s.s.] across the Netherlands in (A-E) 2007 and (F-J) 2008. The ends of the whiskers are set at $1.5 *$ interquartile range (IQR) above the third quartile and $1.5 * \mathrm{IQR}$ below the first quartile. Maximum values exceeding this range are shown as asterisks. 
Table 2. Summary of the set of covariates considered in the hurdle model components.

\begin{tabular}{|c|c|}
\hline Name & Definition \\
\hline \multicolumn{2}{|l|}{ Count model component } \\
\hline Location & Farm (indicator variable), latitude (dd), longitude (dd), altitude (m) \\
\hline Season & The four annual seasons (spring, summer, autumn and winter) as occurring in the north temperate zone \\
\hline Year & Calendar years of the period considered in the present study \\
\hline Ground-measured variables & $\begin{array}{l}\text { Weekly mean values of temperature, relative humidity, pressure, precipitation, evapotranspiration and } \\
\text { hourly mean wind speed }\end{array}$ \\
\hline Satellite-derived variables & Weekly mean values of NDVI, dLST and nLST \\
\hline Host availability data & Cattle density, numbers of cattle, goats and sheep on the light trap site \\
\hline Soil texture features & Percentage of sand, silt, clay and organic carbon in topsoil $(0-30 \mathrm{~cm})$ \\
\hline \multicolumn{2}{|c|}{ Zero hurdle model component } \\
\hline Time & Week, season \\
\hline Ground-measured variables & $\begin{array}{l}\text { Weekly mean values of temperature, relative humidity, wind speed, pressure, precipitation, } \\
\text { evapotranspiration }\end{array}$ \\
\hline Satellite-derived variables & Weekly mean values of NDVI, dLST and nLST \\
\hline
\end{tabular}

dd, decimal degrees; m, meters; NDVI, normalized difference vegetation index; dLST, daytime land surface temperature; nLST, night-time land surface temperature.

active season and which affected Culicoides abundances. This resulted in fitting the zero hurdle model component with time-related and climatic variables only (i.e. including only the covariates that, because they changed during the year, might explain the start of the active season and therefore the probability of observing at least one Culicoides in the trap). By contrast, the count component was fitted with covariates that were characteristics of the sites sampled, whether these were fixed (possibly accounting for the higher prevalence of certain species at specific sites) or variable during the year (possibly accounting for the week to week fluctuations) (Table 2). Full details of the model used, its implementation within the hurdle modelling framework and inference, are provided in Appendix S1 (online).

A separate hurdle model was fitted for the weekly counts (n) of the total Culicoides spp. and of each of the potential BTV-8 vectors, namely the Obsoletus complex (comprising C.obsoletus and C.scoticus), C.chiopterus, C.dewulfi and C. pulicaris s.s. To quantify the amount of collinearity between the covariates, we calculated generalized variance inflation factors (gVIFs), sequentially dropped the covariates with the highest VIF, recalculated the VIFs and repeated this process until all VIFs were $<5$. Variables related to soil texture (sand, silt and clay), cattle density, latitude, temperature (maximum, minimum and mean) and 'farm' showed relatively high VIF values, suggesting that each of them might be related to one or more of the other covariates. Dropping 'farm', sand, maximum and mean temperature and latitude, in that order, reduces the VIF values for the other covariates to below the threshold. The highly heterogeneous Culicoides population sizes caught in a light trap are known to vary in response to local-scale factors (e.g. rate of dung removal from animal holdings, water source availability, etc.), in addition to climatic influences. Actual onfarm measurements of these factors were not available for the present study. For this reason, and because of the collinearity detected, we started with an a priori set of biologically plausible models, rather than evaluating a single model. We then used measures of information and model uncertainty as a basis for model selection. We fitted two types of model with, respectively, indicator 'farm' + climatic variables (type 1), and longitude + altitude + host availability + soil texture + climatic variables (type 2). For C.pulicaris it was possible to fit the type 2 model only because no 'farm' effect can be detected given the little variability between sites. Explanatory variables were removed consecutively in a manual backwardstepwise procedure in order to find the model which, based on a significant reduction of the Akaike information criterion (AIC), best fit the data. The competing models were sorted in terms of their improvements on model fit in comparison with the model with the lowest AIC value, as assessed by the change in AIC $(\triangle \mathrm{AIC})$, and ranked them by AIC weights. The intercept-only model was also included. The AIC weight corresponds to the relative probability that each model was the best model of those being compared (Burnham \& Anderson, 2002). Model checking was carried out by graphical residual analysis rather than numerical methods. The advantage of the first is that it readily illustrates a broad range of complex aspects of the relationship between the model and the data. Graphs of Pearson residuals vs. fitted values and vs. each continuous variable were generated to facilitate visual assessment of the presence of any discernable patterns.

To check whether the models were sensitive to outliers, models including and excluding these observations were assessed in terms of the resultant differences in coefficient estimates, standard errors (SEs) and the AIC. The results differed only slightly and did not alter the conclusions. (Note that the results shown in Tables 4 and 5 refer to the full dataset.) Statistical analysis was performed using $\mathrm{R}$ version 2.14.0 (http://cran.r-project.org/), package 'pscl' (Zeileis et al., 2008). To find evidence of fine-scale spatial variation that was not accounted for, plots of the empirical variogram of the standardized residuals for the hurdle model that performed best for each Culicoides species were examined. This was coupled with the computation of envelopes using data permutation (simulations $n=999$ ) under the assumption of no correlation. If the variogram plot falls within the envelopes, the model is 
presumed to have considerably reduced spatial autocorrelation. The empirical variogram and the variogram envelopes were estimated using the 'geoR' package in R (Ribeiro \& Diggle, 2001).

To detect any temporal patterns that might violate the assumption of independence between observations, model residuals were tested by using the autocorrelation function $(\mathrm{ACF})$ in the R 'STATs' package (R Development Core Team, 2009).

\section{Results}

A total of 906879 Culicoides, representing around 40 species, were trapped in 1541 samples collected during the period of study. The 24 most common species included the five species considered to be proven or potential vectors of BTV in northwest Europe. The Obsoletus complex (C.obsoletus and C. scoticus) predominated in light trap catches and the vector category constituted $44.2 \%$ of the midges collected, followed by $C$.dewulfi $(16.4 \%)$ and C.chiopterus $(16.3 \%)$. The fifth potential vector, C.pulicaris s.s., was rare $(0.1 \%)$.

Model checking indicated that, in terms of overall fit, the models adequately captured the features of the abundance data (over-dispersion in the non-zero observations, excess of zero observations and the correlation between observations from the same site). Residuals diagnostics showed no pattern or trend. Hence, the model used proved to be suitable for analysing the Culicoides abundance time-series dataset that resulted from a protocol of year-round weekly light trapping.

According to our model selection criterion, the models that best describe the data while minimizing information loss appear to be those including the 'farm' indicator variable (Table 3).

For all species, and in both model types 1 and 2, 'season' and the climatic variable dLST gave the highest probabilities for the observation of at least one biting midge in the OVI light trap and are hence likely to govern the commencement of the Culicoides adult active season.

For the count regression component of model types 1 and 2 , the most important variables combined different subsets of covariates, although not all of these were retained in the final model for each species.

Full results of the hurdle models types 1 and 2 for all Culicoides spp. and for each vector species considered in the present study are presented in Tables 4 and 5 .

Best-fit type 1 models (Table 4) identified betweencompartment differences in trap catch abundances of the different species, with the exception of C.pulicaris s.s. In general, Culicoides appeared to be more abundant in the western (nos. 2, 6, 14-16), central (nos. 7, 10) and southern (nos. 18-20) compartments. This general distribution pattern is broadly consistent for the vector species considered, although the magnitude of differences between locations differed. Notably, C.chiopterus and C.dewulfi also appear to be well established in the northwestern (nos. 2-4), central (nos. 6, 7) and southwestern (no. 14) compartments, as do C.obsoletus and C. scoticus in compartments 13, 14 and 17 .
Climatic variables associated with weekly Culicoides counts were coherent across species. Of the set of covariates tested, those determining higher numbers of midges per trap catch were related to temperature (dLST), whereas wind and the evapotranspiration index were associated with lower Culicoides counts. Rain, retained only in the count model of C.chiopterus, and NDVI, for C.obsoletus and C.scoticus, were associated with increasing numbers of these species.

The factor 'season', when retained and although not significant at all levels, suggested that after the spring emergence the majority of species were more abundant before the end of summer. The activity of C. obsoletus and C. scoticus appeared to extend across all seasons with a peak in abundance in summer, whereas C.chiopterus activity peaked later in autumn after a decrease in summer. In comparison with 2007 , vector species were less abundant in 2008.

Best-fit models of type 2 (Table 5) revealed that C.obsoletus, C. scoticus and C.pulicaris s.s. increased from west to east, whereas C.dewulfi decreased in that direction. Numbers of C.obsoletus, C.scoticus and C.dewulfi were positively affected by higher altitude. Seasonal and yearly patterns, as well as effects of climatic variables on the numbers of midges, mirrored those described for models of type 1. All Culicoides species decreased in abundance as cattle density became higher. Host species at a farm, when retained in the model, showed differences in their impact on vector abundance: cattle and sheep seemed to limit and goats to increase the number of Culicoides. A higher fraction of organic material in the soil corresponded to a decrease in numbers of C.obsoletus, C. scoticus and C.chiopterus, but to an increase in numbers of C.dewulfi. An increasing percentage of clay in the soil impacted negatively on $C$. dewulfi.

The variograms of the residuals for each species model considered were all contained by their envelopes (Fig. S1, online), which suggests that no spatial autocorrelation greater than that which might be expected by chance remained after adjusting for the covariates. Therefore, geostatistical models that account for spatial dependency were not explored further in this study.

In the autocorrelation plots, with the exception of lag 0 , which is always 1 by definition, only a few lags fall slightly outside the $95 \%$ confidence interval; this is expected and reflects random fluctuations (Fig. S2, online).

\section{Discussion}

Using an objective surveillance system, valuable data on the distribution and seasonality of Culicoides were collected over 2 years across the Netherlands. Not only will such data be indispensable for predictive modelling, but they might also provide us with a more precise understanding of the ecological niche occupied by each species. The present study attempts to identify the long-term effects of environmental factors on fluctuating Culicoides abundance during the epizootic of bluetongue that swept through the Netherlands in 2007 and 2008 (Elbers et al., 2009).

During those years, proven and potential Culicoides vector species constituted nearly $80 \%$ of the midges collected. 
Table 3. Best subset hurdle regression models of types 1 and 2 for each vector species, including Akaike information criterion (AIC), delta AIC and AIC weight.

\begin{tabular}{|c|c|c|c|c|c|}
\hline \multirow[b]{2}{*}{ Culicoides species } & \multicolumn{5}{|l|}{ Predictors } \\
\hline & Count component & $\begin{array}{l}\text { Zero hurdle } \\
\text { component }\end{array}$ & AIC & $\triangle \mathrm{AIC}$ & $\begin{array}{l}\text { AIC } \\
\text { weight }\end{array}$ \\
\hline \multirow[t]{7}{*}{ Culicoides spp. } & Farm, season, year, dLST, wind & Season, dLST & 12491.47 & 0 & 0.39 \\
\hline & Farm, season, year, dLST, wind, mean humidity & Season, dLST & 12492.37 & 0.9 & 0.24 \\
\hline & Farm, season, year, dLST, NDVI wind, evapotranspiration & Season, dLST & 12492.81 & 1.33 & 0.20 \\
\hline & $\begin{array}{l}\text { Season, year, wind, dLST, rain, mean humidity, evapotranspiration, } \\
\text { cattle density, cattle }(n) \text {, sheep }(n) \text {, goats }(n) \text {, silt, clay, organic }\end{array}$ & Season, dLST & 12614.07 & 122.60 & $<0.001$ \\
\hline & $\begin{array}{l}\text { Season, year, wind, dLST, NDVI, rain, mean humidity, } \\
\text { evapotranspiration, cattle density, cattle }(n) \text {, sheep }(n) \text {, goats }(n) \text {, } \\
\text { longitude, silt, clay, organic }\end{array}$ & Season, dLST & 12617.25 & 125.78 & $<0.001$ \\
\hline & $\begin{array}{l}\text { Season, year, wind, dLST, rain, mean humidity, cattle density, cattle } \\
(n) \text {, sheep }(n) \text {, goats }(n) \text {, silt, clay, organic }\end{array}$ & Season, dLST & 12624.64 & 133.17 & $<0.001$ \\
\hline & Intercept only & Intercept only & 14134.05 & 1642.58 & 0.00 \\
\hline \multirow[t]{6}{*}{ C. obsoletus/scoticus } & Farm, season, year, dLST, wind, NDVI, evapotranspiration & Season, dLST & 10304.71 & 0 & 0.60 \\
\hline & Farm, season, year, dLST, wind, NDVI, evapotranspiration, rain & Season, dLST & 10305.53 & 0.82 & 0.40 \\
\hline & $\begin{array}{l}\text { Season, year, wind, dLST, NDVI, rain, mean humidity, } \\
\text { evapotranspiration, cattle density, cattle }(n) \text {, sheep }(n) \text {, goats }(n) \text {, } \\
\text { altitude, longitude, silt, clay, organic }\end{array}$ & Season, dLST & 10477.83 & 173.12 & $<0.001$ \\
\hline & $\begin{array}{l}\text { Season, year, wind, dLST, rain, mean humidity, evapotranspiration, } \\
\text { cattle density, cattle }(n) \text {, sheep }(n) \text {, goats }(n) \text {, altitude, longitude, } \\
\text { silt, clay, organic }\end{array}$ & Season, dLST & 10478.30 & 173.59 & $<0.001$ \\
\hline & $\begin{array}{l}\text { Season, year, wind, dLST, NDVI, rain, mean humidity, } \\
\text { evapotranspiration, cattle density, cattle }(n) \text {, sheep }(n) \text {, goats }(n) \text {, } \\
\text { longitude, silt, clay, organic }\end{array}$ & Season, dLST & 10479.36 & 174.65 & $<0.001$ \\
\hline & Intercept only & Intercept only & 11896.35 & 1591.64 & 0.00 \\
\hline \multirow[t]{7}{*}{ C. chiopterus } & Farm, season, year, dLST, wind, rain & Season, dLST & 7738.23 & 0 & 0.51 \\
\hline & Farm, season, year, dLST, wind, rain, evapotranspiration & Season, dLST & 7738.95 & 0.72 & 0.35 \\
\hline & Farm, season, year, dLST, NDVI, wind, rain, evapotranspiration, & Season, dLST & 7740.86 & 2.63 & 0.14 \\
\hline & $\begin{array}{l}\text { Year, wind, dLST, NDVI, rain, mean humidity, evapotranspiration, } \\
\text { cattle }(n) \text {, goats }(n) \text {, silt, clay, organic }\end{array}$ & Season, dLST & 7787.26 & 49.03 & $<0.001$ \\
\hline & $\begin{array}{l}\text { Year, wind, dLST, NDVI, rain, mean humidity, evapotranspiration, } \\
\text { cattle }(n) \text {, goats }(n) \text {, altitude, silt, clay, organic }\end{array}$ & Season, dLST & 7788.18 & 49.95 & $<0.001$ \\
\hline & $\begin{array}{l}\text { Year, wind, dLST, NDVI, rain, mean humidity, evapotranspiration, } \\
\text { cattle }(n) \text {, sheep }(n) \text {, goats }(n) \text {, altitude, silt, clay, organic }\end{array}$ & Season, dLST & 7789.62 & 51.39 & $<0.001$ \\
\hline & Intercept only & Intercept only & 8854.77 & 1116.54 & 0.00 \\
\hline \multirow[t]{6}{*}{ C. dewulfi } & Farm, year, wind, dLST & Season, dLST & 7556.97 & 0 & 0.95 \\
\hline & Farm, year, NDVI, dLST, wind, rain, evapotranspiration & Season, dLST & 7562.68 & 5.71 & 0.05 \\
\hline & $\begin{array}{l}\text { Year, wind, dLST, mean humidity, cattle }(n) \text {, sheep }(n) \text {, altitude, } \\
\text { longitude, clay, organic }\end{array}$ & Season, dLST & 7634.17 & 77.2 & $<0.001$ \\
\hline & $\begin{array}{l}\text { Year, wind, dLST, mean humidity, rain, cattle }(n) \text {, sheep }(n) \text {, } \\
\text { altitude, longitude, clay, organic }\end{array}$ & Season, dLST & 7634.93 & 77.96 & $<0.001$ \\
\hline & $\begin{array}{l}\text { Year, wind, dLST, mean humidity, rain, cattle }(n) \text {, sheep }(n) \text {, goats } \\
(n) \text {, altitude, longitude, clay, organic }\end{array}$ & Season, dLST & 7636.02 & 79.05 & $<0.001$ \\
\hline & Intercept only & Intercept only & 8635.42 & 1078.45 & 0.00 \\
\hline \multirow[t]{7}{*}{ C. pulicaris s.s. } & Wind, cattle density, sheep $(n)$, goats $(n)$, longitude & Season, dLST & 1028.309 & 0 & 0.44 \\
\hline & Year, wind, cattle density, sheep $(n)$, goats $(n)$, longitude & Season, dLST & 1029.659 & 1.35 & 0.22 \\
\hline & Year, wind, rain, cattle density, sheep $(n)$, goats $(n)$, longitude & Season, dLST & 1029.833 & 1.52 & 0.21 \\
\hline & $\begin{array}{l}\text { Year, wind, dLST, rain, evapotranspiration, cattle density, sheep }(n) \text {, } \\
\text { goats }(n) \text {, longitude }\end{array}$ & Season, dLST & 1031.111 & 2.80 & 0.11 \\
\hline & Year, wind, dLST, rain, cattle density, sheep $(n)$, goats $(n)$, longitude & Season, dLST & 1031.627 & 3.32 & 0.08 \\
\hline & $\begin{array}{l}\text { Year, wind, dLST, rain, evapotranspiration, cattle density, sheep }(n) \text {, } \\
\text { goats }(n) \text {, longitude, clay }\end{array}$ & Season, dLST & 1032.427 & 4.12 & 0.06 \\
\hline & Intercept only & Intercept only & 1120.61 & 92.30 & 0.00 \\
\hline
\end{tabular}

dLST, daytime land surface temperature; NDVI, normalized difference vegetation index. 
Table 4. Regression coefficients estimates, standard errors (SEs) and $P$-values for factors retained in the best hurdle model of type 1 for each vector species considered.

\begin{tabular}{|c|c|c|c|c|c|c|c|c|}
\hline \multirow[b]{2}{*}{ Name } & \multicolumn{2}{|l|}{ Culicoides spp. } & \multicolumn{2}{|c|}{ C. obsoletus/scoticus } & \multicolumn{2}{|l|}{ C. chiopterus } & \multicolumn{2}{|l|}{ C. dewulfi } \\
\hline & $\beta \pm \mathrm{SE}$ & $\operatorname{Pr}(>|z|)$ & $\beta \pm \mathrm{SE}$ & $\operatorname{Pr}(>|z|)$ & $\beta \pm \mathrm{SE}$ & $\operatorname{Pr}(>|z|)$ & $\beta \pm \mathrm{SE}$ & $\operatorname{Pr}(>|z|)$ \\
\hline \multicolumn{9}{|c|}{ Count model coefficients (truncated negative binomial with log link) } \\
\hline (Intercept) & $1.75 \pm 0.61$ & 0.001 & $-1.71 \pm 0.78$ & 0.02 & $-0.30 \pm 1.21$ & 0.80 & $-2.47 \pm 0.80$ & 0.002 \\
\hline Farm 1A & Ref & - & Ref & - & Ref & - & Ref & - \\
\hline Farm 1B & $-0.21 \pm 0.37$ & 0.57 & $1.55 \pm 0.39$ & $<0.001$ & $1.62 \pm 0.71$ & 0.02 & $2.08 \pm 0.73$ & 0.002 \\
\hline Farm 2 & $1.53 \pm 0.35$ & $<0.001$ & $3.30 \pm 0.52$ & $<0.001$ & $3.03 \pm 0.75$ & $<0.001$ & $4.54 \pm 0.73$ & 0.004 \\
\hline Farm 3 & $0.41 \pm 0.36$ & 0.25 & $0.69 \pm 0.38$ & 0.07 & $1.70 \pm 0.73$ & 0.02 & $3.21 \pm 0.73$ & $<0.001$ \\
\hline Farm 4 & $0.81 \pm 0.44$ & 0.06 & $2.24 \pm 0.44$ & $<0.001$ & $2.41 \pm 0.82$ & 0.003 & $4.17 \pm 0.79$ & $<0.001$ \\
\hline Farm 5 & $-0.11 \pm 0.36$ & 0.75 & $1.76 \pm 0.38$ & $<0.001$ & $0.99 \pm 0.67$ & 0.13 & $2.90 \pm 0.72$ & $<0.001$ \\
\hline Farm 6 & $1.74 \pm 0.36$ & $<0.001$ & $3.22 \pm 0.38$ & $<0.001$ & $1.20 \pm 0.72$ & 0.09 & $4.73 \pm 0.73$ & $<0.001$ \\
\hline Farm 7 & $2.70 \pm 0.37$ & $<0.001$ & $4.85 \pm 0.38$ & $<0.001$ & $3.85 \pm 0.76$ & $<0.001$ & $4.85 \pm 0.74$ & $<0.001$ \\
\hline Farm 8 & $-0.13 \pm 0.46$ & 0.77 & $1.08 \pm 0.46$ & 0.02 & $0.83 \pm 0.84$ & 0.32 & $4.20 \pm 0.82$ & $<0.001$ \\
\hline Farm 9 & $-0.22 \pm 0.43$ & 0.60 & $0.05 \pm 0.42$ & 0.90 & $0.32 \pm 0.74$ & 0.66 & $2.42 \pm 0.80$ & $<0.001$ \\
\hline Farm 10 & $0.78 \pm 0.39$ & 0.05 & $1.92 \pm 0.38$ & $<0.001$ & $1.06 \pm 0.75$ & 0.15 & $5.42 \pm 0.75$ & $<0.001$ \\
\hline Farm 11 & $-1.17 \pm 0.46$ & 0.01 & $0.28 \pm 0.47$ & 0.54 & $0.33 \pm 0.83$ & 0.69 & $2.32 \pm 0.95$ & 0.02 \\
\hline Farm 12 & $-1.50 \pm 0.44$ & $<0.01$ & $-0.12 \pm 0.43$ & 0.76 & $0.31 \pm 0.78$ & 0.68 & $0.11 \pm 0.83$ & 0.89 \\
\hline Farm 13 & $0.38 \pm 0.49$ & 0.43 & $2.83 \pm 0.50$ & $<0.001$ & $0.49 \pm 0.89$ & 0.57 & $3.20 \pm 0.94$ & $<0.001$ \\
\hline Farm 14 & $1.28 \pm 0.34$ & $<0.01$ & $2.42 \pm 0.36$ & $<0.001$ & $2.96 \pm 0.77$ & $<0.001$ & $3.28 \pm 0.70$ & $<0.001$ \\
\hline Farm 15 & $-2.34 \pm 0.45$ & $<0.001$ & $-0.59 \pm 0.47$ & 0.20 & $-1.50 \pm 0.78$ & 0.05 & $0.003 \pm 0.88$ & 0.99 \\
\hline Farm 16 & $-1.83 \pm 0.44$ & $<0.001$ & $0.09 \pm 0.44$ & 0.83 & $-1.47 \pm 0.81$ & 0.07 & $1.61 \pm 0.83$ & 0.05 \\
\hline Farm 17 & $0.19 \pm 0.44$ & 0.66 & $2.23 \pm 0.43$ & $<0.001$ & $0.02 \pm 0.82$ & 0.97 & $3.27 \pm 0.86$ & $<0.001$ \\
\hline Farm 18 & $0.85 \pm 0.45$ & 0.06 & $3.06 \pm 0.45$ & $<0.001$ & $1.19 \pm 0.83$ & 0.15 & $3.53 \pm 0.83$ & $<0.001$ \\
\hline Farm 19 & $2.00 \pm 0.38$ & $<0.001$ & $3.31 \pm 0.39$ & $<0.001$ & $3.23 \pm 0.72$ & $<0.001$ & $5.83 \pm 0.72$ & $<0.001$ \\
\hline Farm 20 & $1.82 \pm 0.37$ & $<0.001$ & $3.88 \pm 0.37$ & $<0.001$ & $1.05 \pm 0.75$ & 0.16 & $6.07 \pm 0.73$ & $<0.001$ \\
\hline Spring & Ref & - & Ref & - & Ref & - & - & - \\
\hline Summer & $0.39 \pm 0.18$ & 0.03 & $1.17 \pm 0.15$ & $<0.001$ & $-0.49 \pm 0.28$ & 0.07 & - & - \\
\hline Autumn & $0.23 \pm 0.29$ & 0.42 & $0.64 \pm 0.28$ & 0.02 & $0.16 \pm 0.48$ & 0.72 & - & - \\
\hline Winter & $-3.00 \pm 0.63$ & $<0.001$ & $-1.80 \pm 0.62$ & 0.004 & $-8.74 \pm 112.51$ & 0.93 & - & - \\
\hline Year 2007 & Ref & - & Ref & - & Ref & - & Ref & - \\
\hline Year 2008 & $-0.60 \pm 0.17$ & $<0.001$ & $-0.75 \pm 0.16$ & $<0.001$ & $-0.53 \pm 0.26$ & 0.04 & $-1.05 \pm 0.24$ & $<0.001$ \\
\hline Evapotranspiration & - & - & $-0.30 \pm 0.11$ & 0.008 & - & - & - & - \\
\hline NDVI & - & - & $1.30 \pm 0.60$ & 0.03 & - & - & - & - \\
\hline Wind & $-0.22 \pm 0.04$ & $<0.001$ & $-0.15 \pm 0.04$ & $<0.001$ & $-0.23 \pm 0.07$ & 0.001 & $-0.17 \pm 0.07$ & 0.01 \\
\hline Rain & - & - & - & - & $0.02 \pm 0.01$ & 0.02 & - & - \\
\hline dLST & $0.21 \pm 0.02$ & $<0.001$ & $0.21 \pm 0.02$ & $<0.001$ & $0.16 \pm 0.03$ & $<0.001$ & $0.17 \pm 0.02$ & $<0.001$ \\
\hline Log (theta) & $-1.37 \pm 0.08$ & $<0.001$ & $-1.19 \pm 0.08$ & $<0.001$ & $-2.39 \pm 0.28$ & $<0.001$ & $-2.06 \pm 0.20$ & $<0.001$ \\
\hline \multicolumn{9}{|c|}{ Zero hurdle model coefficients (binomial with cloglog link) } \\
\hline (Intercept) & $-2.80 \pm 0.23$ & $<0.001$ & $-2.75 \pm 0.22$ & $<0.001$ & $-3.42 \pm 0.24$ & $<0.001$ & $-4.28 \pm 0.27$ & $<0.001$ \\
\hline Spring & Ref & - & Ref & - & Ref & - & Ref & - \\
\hline Summer & $0.76 \pm 0.11$ & $<0.001$ & $0.64 \pm 0.10$ & $<0.001$ & $0.51 \pm 0.09$ & $<0.001$ & $0.85 \pm 0.10$ & $<0.001$ \\
\hline Autumn & $1.25 \pm 0.15$ & $<0.001$ & $1.10 \pm 0.15$ & $<0.001$ & $1.19 \pm 0.15$ & $<0.001$ & $1.53 \pm 0.17$ & $<0.001$ \\
\hline Winter & $-1.49 \pm 0.31$ & $<0.001$ & $-1.59 \pm 0.32$ & $<0.001$ & $-3.49 \pm 1.01$ & $<0.01$ & $-16.3 \pm 844.7$ & 0.98 \\
\hline $\mathrm{dLST}$ & $0.16 \pm 0.01$ & $<0.001$ & $0.15 \pm 0.01$ & $<0.001$ & $0.16 \pm 0.01$ & $<0.001$ & $-0.18 \pm 0.01$ & $<0.001$ \\
\hline
\end{tabular}

dLST, daytime land surface temperature; NDVI, normalized difference vegetation index.

The species remained active continuously for 6-9 months, including late summer and autumn when outbreaks of bluetongue peaked. Only one of the five proven vector species, namely C.pulicaris s.s., was consistently rare. After spring had commenced, Culicoides vector populations developed rapidly and thereafter, throughout the summer and autumn, remained continually active and maintained high abundance levels. In particular, C. obsoletus/C. scoticus appeared to peak in summer, as did C.chiopterus in autumn, confirming previous results for farm-associated species in northern Europe (Sanders etal., 2011). As Meiswinkel et al. (2013) demonstrate, many univoltine and bivoltine species (completing one or two generations per year) disappeared towards the end of the summer, which means that only the multivoltine species, including all those acting as vectors of BTV, remained active until week 45. This, along with the results from the hurdle regression model, indicates that multivoltine species respond adaptively to any increase in temperature within their respective breeding habitats.

The hurdle model has not been previously applied to an analysis of Culicoides surveillance abundance data collected throughout the year. The process of considering count outcomes generated by two systematically different statistical procedures was sufficiently flexible to describe the relationship 
Table 5. Regression coefficients estimates, standard errors (SEs) and $P$-values for factors retained in the best hurdle model of type 2 for each vector species considered.

\begin{tabular}{|c|c|c|c|c|c|c|c|c|c|c|}
\hline \multirow[b]{2}{*}{ Name } & \multicolumn{2}{|l|}{ Culicoides spp. } & \multicolumn{2}{|c|}{ C. obsoletus/scoticus } & \multicolumn{2}{|l|}{ C. chiopterus } & \multicolumn{2}{|l|}{ C. dewulfi } & \multicolumn{2}{|l|}{ C. pulicaris s.s. } \\
\hline & $\beta \pm \mathrm{SE}$ & $\operatorname{Pr}(>|z|)$ & $\beta \pm \mathrm{SE}$ & $\operatorname{Pr}(>|z|)$ & $\beta \pm \mathrm{SE}$ & $\operatorname{Pr}(>|z|)$ & $\beta \pm \mathrm{SE}$ & $\operatorname{Pr}(>|z|)$ & $\beta \pm \mathrm{SE}$ & $\operatorname{Pr}(>|z|)$ \\
\hline \multicolumn{11}{|c|}{ Count model coefficients (truncated negative binomial with log link) } \\
\hline (Intercept) & $4.43 \pm 0.73$ & $<0.01$ & $0.03 \pm 1.40$ & 0.98 & $4.39 \pm 1.17$ & $<0.001$ & $5.25 \pm 1.67$ & 0.01 & $-3.66 \pm 2.41$ & 0.13 \\
\hline Longitude & - & - & $0.54 \pm 0.22$ & 0.01 & - & - & $-0.50 \pm 0.23$ & 0.05 & $1.52 \pm 0.42$ & $<0.001$ \\
\hline Altitude & - & - & $0.01 \pm 0.01$ & 0.06 & - & - & $0.012 \pm 0.001$ & $<0.001$ & - & - \\
\hline Clay & $-0.01 \pm 0.008$ & 0.10 & $0.005 \pm 0.01$ & 0.62 & $0.03 \pm 0.01$ & 0.06 & $-0.04 \pm 0.01$ & $<0.001$ & - & - \\
\hline Silt & $0.013 \pm 0.007$ & 0.07 & $-0.004 \pm 0.01$ & 0.68 & $-0.02 \pm 0.01$ & 0.06 & - & - & - & - \\
\hline Organic & $-0.01 \pm 0.008$ & 0.18 & $-0.02 \pm 0.01$ & 0.03 & $-0.03 \pm 0.01$ & $<0.001$ & $0.06 \pm 0.01$ & $<0.001$ & - & - \\
\hline Cattle density & $-0.23 \pm 0.06$ & $<0.001$ & $-0.31 \pm 0.09$ & $<0.001$ & - & - & $-0.007 \pm 0.001$ & $<0.001$ & $-0.72 \pm 0.15$ & $<0.001$ \\
\hline Cattle, $n$ & $-0.003 \pm 0.001$ & 0.01 & $-0.002 \pm 0.001$ & 0.05 & $-0.001 \pm 0.001$ & 0.05 & - & - & - & - \\
\hline Sheep, $n$ & $-0.006 \pm 0.003$ & 0.05 & $-0.02 \pm 0.003$ & $<0.001$ & - & - & $-0.01 \pm 0.004$ & 0.05 & $-0.02 \pm 0.01$ & 0.08 \\
\hline Goats, $n$ & $0.21 \pm 0.04$ & $<0.001$ & $0.27 \pm 0.04$ & $<0.001$ & $0.25 \pm 0.05$ & $<0.001$ & - & - & $0.33 \pm 0.12$ & 0.01 \\
\hline Spring & Ref & - & Ref & - & - & - & - & - & - & - \\
\hline Summer & $0.65 \pm 0.21$ & 0.01 & $1.29 \pm 0.18$ & $<0.001$ & - & - & - & - & - & - \\
\hline Autumn & $-0.14 \pm 0.33$ & 0.66 & $0.03 \pm 0.33$ & 0.93 & - & - & - & - & - & - \\
\hline Winter & $-3.46 \pm 0.66$ & $<0.001$ & $-2.22 \pm 0.70$ & 0.01 & - & - & - & - & - & - \\
\hline Year 2007 & Ref & - & Ref & - & Ref & - & Ref & - & - & - \\
\hline Year 2008 & $-0.26 \pm 0.19$ & 0.17 & $-0.67 \pm 0.20$ & $<0.001$ & $-0.51 \pm 0.26$ & 0.05 & $-1.36 \pm 0.28$ & $<0.001$ & - & - \\
\hline Humidity & $-0.02 \pm 0.004$ & $<0.001$ & $-0.01 \pm 0.004$ & 0.05 & $-0.03 \pm 0.006$ & $<0.001$ & $-0.01 \pm 0.005$ & 0.01 & - & - \\
\hline NDVI & - & - & $0.77 \pm 0.48$ & 0.11 & $-2.38 \pm 0.72$ & $<0.001$ & - & - & - & - \\
\hline Evapotranspiration & $-0.50 \pm 0.14$ & $<0.001$ & $-0.80 \pm 0.14$ & $<0.001$ & $-0.31 \pm 0.17$ & 0.08 & - & - & - & - \\
\hline Wind & $-0.26 \pm 0.04$ & $<0.001$ & $-0.26 \pm 0.05$ & $<0.001$ & $-0.31 \pm 0.06$ & $<0.001$ & $-0.26 \pm 0.08$ & $<0.001$ & $-0.56 \pm 0.18$ & 0.01 \\
\hline Rain & $<0.001 \pm 0.008$ & 0.97 & $-0.02 \pm 0.01$ & 0.07 & $0.02 \pm 0.01$ & 0.08 & - & - & - & - \\
\hline dLST & $0.30 \pm 0.03$ & $<0.001$ & $0.29 \pm 0.03$ & $<0.001$ & $0.23 \pm 0.03$ & $<0.001$ & $0.23 \pm 0.031$ & $<0.001$ & - & - \\
\hline $\log ($ theta) & $-1.69 \pm 0.10$ & $<0.001$ & $-1.71 \pm 0.12$ & $<0.001$ & $-3.54 \pm 0.80$ & $<0.001$ & $-3.08 \pm 0.50$ & $<0.001$ & $-1.05 \pm 0.52$ & 0.05 \\
\hline \multicolumn{11}{|c|}{ Zero hurdle model coefficients (binomial with cloglog link) } \\
\hline (Intercept) & $-2.80 \pm 0.23$ & $<0.001$ & $-2.75 \pm 0.22$ & $<0.001$ & $-3.43 \pm 0.25$ & $<0.001$ & $-4.28 \pm 0.28$ & $<0.001$ & $-4.56 \pm 0.67$ & $<0.001$ \\
\hline Spring & Ref & - & Ref & - & Ref & - & Ref & - & Ref & - \\
\hline Summer & $0.76 \pm 0.12$ & $<0.001$ & $0.65 \pm 0.10$ & $<0.001$ & $0.51 \pm 0.09$ & $<0.001$ & $0.86 \pm 0.10$ & $<0.001$ & $0.02 \pm 0.24$ & 0.91 \\
\hline Autumn & $1.25 \pm 0.16$ & $<0.001$ & $1.10 \pm 0.15$ & $<0.001$ & $1.19 \pm 0.15$ & $<0.001$ & $1.54 \pm 0.17$ & $<0.001$ & $-0.18 \pm 0.47$ & 0.69 \\
\hline Winter & $-1.50 \pm 0.31$ & $<0.001$ & $-1.61 \pm 0.33$ & $<0.001$ & $-3.49 \pm 1.01$ & $<0.001$ & $-16.30 \pm 844.7$ & 0.98 & $-15.5 \pm 882$ & 0.98 \\
\hline dLST & $0.16 \pm 0.010$ & $<0.001$ & $0.15 \pm 0.01$ & $<0.001$ & $0.16 \pm 0.02$ & $<0.001$ & $0.18 \pm 0.02$ & $<0.001$ & $0.10 \pm 0.03$ & $<0.001$ \\
\hline
\end{tabular}

dLST, daytime land surface temperature; NDVI, normalized difference vegetation index.

between certain environmental factors and weekly Culicoides abundances across locations (truncated-at-zero negative binomial regression), and ecologically sensible in the interpretation of the main factors governing the commencement of Culicoides activity at the beginning of each season (binomial regression).

Patterns of abundance in vector Culicoides species were explained by a combination of climatic-both groundmeasured and satellite-derived - and non-climatic factors. The relationships between Culicoides vector abundances and meteorological conditions reflect findings elsewhere in the world, in which the effects of temperature-related variables and wind were confirmed as the factors with the most influence on Culicoides activity and dispersal as measured by suction light traps (Peng et al., 1992; Baylis et al., 1998; Purse et al., 2004b). The availability of moisture (NDVI, evapotranspiration and precipitation) is the most important variable after temperature in the promotion or disruption of Culicoides larval development as a result of site-specific edaphic factors and differences in species specific-breeding habitats. Culicoides chiopterus abundances correlated positively with increased rainfall, whereas those of C. pulicaris s.s. and C. obsoletus/C. scoticus were affected positively by NDVI and negatively by evapotranspiration, as in other locations in Europe (Purse et al., 2004b; Kluiters et al., 2013).
The geographical patterns of vector prevalence in the Netherlands are posited not to be entirely disjunctive, but to show overlap because the terrain is largely uniform and human activity has had a tremendous impact on the soil profile and properties (van der Veer, 2006). Soil texture, referring to the relative proportions of organic material, sand, silt and clay particles, is directly linked to its water-holding capacity, nutrient retention and drainage. Finely textured clayey soils are known to absorb water very slowly and to retain moisture and nutrients. Coarsely textured sandy soils drain quickly and do not hold nutrients well, whereas the larger the soil organic matter content, the lower the drainage rate will be. The fraction of organic carbon is one of the best indicators of the health status of soil and a growing percentage is associated with fertile areas with a good structure (e.g. arable land) (HSWD, FAO/IIASA/ISRIC/ISS-CAS/JRC, 2009). Stated broadly, our study indicated that Culicoides species, in response to moisture availability, occur most abundantly in low-lying coastal areas in the northwest, west and southwest, and the central and southern sites, but are less abundant in the elevated northeast, east and southeast parts of the country, which are drier and better drained. Culicoides obsoletus and C. scoticus were negatively linked to soil rich in organic carbon and were thus less abundant in arable areas; this 
supports earlier findings indicating that these species favour a 'non-arable' habitat, such as forest leaf litter (Conte et al., 2007). Abundances of C.chiopterus and C.dewulfi, both of which breed in cattle dung, appear to be influenced differently by the organic and clay contents of topsoil. Culicoides dewulfi favours soil that is less moisture-retentive and rich in nutrients, whereas C.chiopterus prefers soil with a nutrient-retentive texture (clayey), but a low organic matter fraction. It was not possible for the current study to make comparisons with recent studies on Palaearctic Culicoides because these species were not sampled (Harrup et al., 2013), or because morphological speciation was performed at group level (Purse et al., 2012) and a different trapping technique was used (Sanders etal., 2011). The possibility cannot be excluded that the identification of alternative breeding sites necessitates on-site data collection and that habitat suitability may also be revealed by other landscape components that could be delineated by the use of satellite image-generated maps of land use or land cover class (Sithiprasasna et al., 2005).

The present work also revealed C.pulicaris s.s. to be rare overall and be consistently absent from some areas (sites $1 \mathrm{~A}$ and 2), but whether the absence of this species should be ascribed to a non-favourable niche is unclear. The gaps in the distribution of this species, along with its very low abundances, indicate that C.pulicaris s.s. is unable to penetrate into all areas and to satisfy the three inter-related elements (abundance, seasonal persistence and multivoltinism) that a competent vector appears to possess. The areas free of C.pulicaris s.s. identified in this survey are worthy of being characterized more precisely.

The negative impact of cattle density, numbers of cattle and sheep, as opposed to the positive effect of goats, seems paradoxical, given that the presence of hosts is a prerequisite for the survival of blood-sucking midges. Because all the sites sampled during the surveillance programme were mediumsize livestock holdings and cattle density was measured at the compartment scale, we are not able to determine whether the presence of farm animals was a limiting factor on fluctuating Culicoides species-specific abundance at the local scale or whether it represented a proxy for land use, as suggested previously (Sanders etal., 2011). The only conclusion we can draw is that the present results would indicate an important role of multiple hosts on abundances and prevalences of vector species. Hence, the picture that emerges does not alter but refines that for farm-associated Culicoides species in the Netherlands provided earlier by Takken et al. (2008). These authors reported species of both the C.obsoletus and C.pulicaris groups to be strongly associated with livestock farm habitats. Addressing the differences between the two studies is complicated for at least two reasons: firstly, the sites selected for the national surveillance programme considered in the present study included mainly cattle, which contrasts strongly with the greater variety of areas studied by Takken et al. (2008); secondly, to treat midges at group rather than species level may obscure some of the key factors that underlie species-specific abundances.

Variance inflation factors were computed to identify relevant collinear variables. However, this resulted in problems in identifying which covariates were driving the system: those retained or those eliminated. We used a formal approach from information theory to select, amongst an a priori defined set of biologically plausible models, those that best explain the data. The differences in model fitting between the models including the 'farm' indicator variable and those with sitespecific attributes (related to geography, hosts and soil type) can be hypothesized as reflecting farm management factors and characteristics of the site sampled that were not accounted for in the present study. Examples of such factors are: manure storage; the presence of water sources; the presence and type of vegetation surrounding the farm and the pasture (open or wooded), and the distance of the light trap from the livestock (Rigot et al., 2012b; Kluiters et al., 2013). We cannot address this issue without conducting a controlled experiment. These factors will need to be considered in future attempts to further refine understanding of the overlapping environmental processes that underlie complex Culicoides communities.

Light-trapping protocols usually retrieve abundance data for multiple species from a single night's sampling and, although these data have been found to be inaccurate in reflecting the host-seeking behaviour of C.chiopterus (Carpenter et al., 2008; Viennet et al., 2011), they are considered to represent proportionally the size of the local midge populations found at a sampling site, multiplied by activity rate and trap efficiency. Up to 22 species have been found to co-occur, but seldom co-dominantly, at the same site in the Netherlands (F. Scolamacchia \& R. Meiswinkel, personal communication, 2010); similar numbers have been reported elsewhere in northern Europe (Blackwell et al., 1992). These numbers are considerably lower than those found in the tropics and may simply reflect lower niche diversity at more temperate latitudes. Seasonal periods of peak abundance overlap in many, but not all, species, and there is also evidence for temporal segregation over the 24-h cycle, with some species becoming active earlier in the day than others (Viennet et al., 2012). Such information, together with detailed seasonal demographic data and records of the respective breeding habitats, should help to further clarify the predominance of certain species over others in specific areas.

The present study uses the unique opportunity provided by the national surveillance programme to obtain a broad insight into Dutch Culicoides fauna phenology. However, the short time series ( 2 years) and the small number of locations sampled (21 in 2007 and 11 in 2008) render it difficult to interpret and generalize the findings in order to elucidate the differences and similarities with previous observations in Culicoides field vectors since midge-borne diseases entered Europe. It is also true that data referring to a multi-host/multivector episystem such as that delineated in northern European countries should include hosts additional to those cited in the present study, specifically horses and wildlife species (e.g. roe deer, red deer and wild boar) (Tabachnick, 2010). Finally, including site-level factors such as those related to the microhabitat, artificial breeding sites in the direct vicinity of the trap and farm management might enhance our understanding of species-specific phonological traits that should correlate with the appearance of the relevant disease in the vertebrate host. In fact, findings of local vector prevalence and increased abundance that do not seem to be linked to soil, but more 
intimately to the prevalence of hosts, may favour the clustering of bluetongue cases within herds. It might be the case that the latter, by contrast with a totally random distribution of the disease, may depend on the species' reproductive biology. Clustering at herd level is more likely to occur at locations where well-known livestock-associated species are prevalent rather than at sites where predominant species must migrate back and forth between the larval habitat and the blood source (the animal).

The processes linked to the emergence and subsequent spread of bluetongue in northern Europe remain difficult to unravel, not least as a result of a poor understanding of vector dynamics, especially at the local level, and the lack of historical data on midge densities in nearly all of the areas affected during an epidemic (Purse et al., 2008). This makes it difficult to establish whether important changes, if any, have occurred in Culicoides with regard to population size and the number of generations completed annually, and whether these, along with local and annual climatic fluctuations, exert a transient impact on the spread of bluetongue. The implementation of functional risk models for midge-borne diseases is thus of great relevance, given the diversity and value of the livestock population at risk (Hartemink etal., 2009; Backer \& Nodelijk, 2011; Guis et al., 2012).

The present study has considerable potential and its insights could be applied to initiate diverse modelling approaches in order to more accurately predict Culicoides vector abundance at different space and time scales. In conjunction with the recent advent of molecular identification of biting midges, this approach may strengthen ecological studies on habitat preferences, especially among sibling species, which have so far been poorly explored (Harrup et al., 2013). It is also important to consider how biological and climatic processes that influence adult midge behaviour interact with the dynamics of BTV infection, and the practical applications of this for defining the optimal size of the geographic unit for insect surveillance programmes.

\section{Supporting Information}

Additional Supporting Information may be found in the online version of this article under the DOI reference: DOI: $10.1111 /$ mve. 12028

\section{Appendix S1. Supporting information.}

Figure S1. Binned omnidirectional variogram computed using the standardized residuals derived from the best hurdle model 1) and 2), for each species of Culicoides. Model 1): a. Culicoides spp., b. Culicoides obsoletus/scoticus, c. Culicoides chiopterus, d. Culicoides dewulfi. Model 2): e. Culicoides spp., f. Culicoides obsoletus/scoticus, g. Culicoides chiopterus, h. Culicoides dewulfi, i. Culicoides pulicaris s.s., The pointwise 95\% limits (dashed lines) were obtained from 999 simulations where the residuals were randomly allocated to the spatial locations, and the empirical variogram computed for each simulation (solid line). Separation distance is given in $\mathrm{Km}$.
Figure S2. Autocorrelation plot computed using the standardized residuals derived from the best hurdle model 1) and 2), for each species of Culicoides. Model 1): a. Culicoides spp., b. Culicoides obsoletus/scoticus, c. Culicoides chiopterus, d. Culicoides dewulfi. Model 2): e. Culicoides spp., f. Culicoides obsoletus/scoticus, g. Culicoides chiopterus, h. Culicoides dewulfi, i. Culicoides pulicaris s.s. The blue dashed horizontal lines are $95 \%$ confidence limits.

\section{Acknowledgements}

The authors thank the Netherlands Food and Consumer Product Safety Authority (NVWA) for granting access to the vector data collected under its auspices. This study was commissioned and funded by the Dutch Ministry of Economic Affairs, Agriculture and Innovation (WOT project no. 01-003-040 and KB-12-005.01-0.14). We thank Gert-Jan Boender [Central Veterinary Institute of Wageningen University and Research (CVI-WUR)] and Daniela Cianci (Department of Farm Animal Health, Utrecht University) for their support in producing the map in Fig. 1. FS would like to thank Linda McPhee (Linda McPhee Consulting, http://www.lindamcpheeconsulting.com) for fruitful discussions, invaluable advice and professional support in preparing this manuscript. We also thank four anonymous reviewers for their comments during the peer review process.

\section{References}

Acevedo, P., Ruiz-Fons, F., Estrada, R., Marquez, A.L., Miranda, M.A., Gortázar, C. \& Lucientes, J. (2010) A broad assessment of factors determining Culicoides imicola abundance: modelling the present and forecasting its future in climate change scenarios. PLoS One, 5, e14236.

AviaGIS (2010) Agriculture and Veterinary Information and Analysis, Avia-geoExplorer DVD Tool, Version 2010. http://www.aviagis.com/ [Accessed 7 May 2013].

Backer, J.A. \& Nodelijk, G. (2011) Transmission and control of African horse sickness in the Netherlands: a model analysis. PLoS One, 6, e23066.

Baylis, M., El Hasnaoui, H., Bouayoune, H., Touti, J. \& Mellor, P.S. (1997) The spatial and seasonal distribution of African horse sickness and its potential Culicoides vectors in Morocco. Medical and Veterinary Entomology, 11, 203-212.

Baylis, M., Bouayoune, H., Touti, J. \& El Hasnaoui, H. (1998) Use of climatic data and satellite imagery to model the abundance of Culicoides imicola, the vector of African horse sickness, in Morocco. Medical and Veterinary Entomology, 12, 255-266.

Baylis, M., Mellor, P.S., Wittman, E.J. \& Rogers, D.J. (2001) Prediction of areas around the Mediterranean at risk of bluetongue by modelling the distribution of its vector using satellite imaging. Veterinary Record, 149, 639-643.

Birley, M.H. \& Boorman, J.P.T. (1982) Estimating the survival and biting rates of haematophagous insects, with particular reference to the Culicoides obsoletus Group (Diptera, Ceratopogonidae) in southern England. Journal of Animal Ecology, 51, 135-148.

Blackwell, A., Mordue (Luntz), A.J., Young, M.R. \& Mordue, W. (1992) Bivoltinism and reproductive characteristics of the Scottish 
biting midge, Culicoides impunctatus Goetghebuer (Diptera: Ceratopogonidae). Bulletin of Entomological Research, 82, 299-306.

Braverman, Y., Galun, R. \& Ziv, M. (1974) Breeding sites of some Culicoides species (Diptera, Ceratopogonidae) in Israel. Mosquito News, 34, 303-308.

Burnham, K.P. \& Anderson, D.R. (2002) Model Selection and Multimodel Inference: A Practical Information-Theoretic Approach, 2nd edn. Springer-Verlag, New York, NY.

Calistri, P., Goffredo, M., Caporale, V. \& Meiswinkel, R. (2003) The distribution of Culicoides imicola in Italy: application and evaluation of current Mediterranean models based on climate. Journal of Veterinary Medicine B, 50, 132-138.

Calvete, C., Estrada, R., Miranda, M.A., Borras, D., Calvo, J.H. \& Lucientes, J. (2009) Ecological correlates of bluetongue virus in Spain: predicted spatial occurrence and its relationship with the observed abundance of the potential Culicoides spp. vector. Veterinary Journal, 182, 235-243.

Cameron, A.C. \& Trivedi, P.K. (1998) Regression Analysis of Count Data. Cambridge University Press, Cambridge.

Campbell, J.B. (1996) Introduction to Remote Sensing. Taylor \& Francis, London.

Capela, R., Purse, B.V., Pena, I. etal. (2003) Spatial distribution of Culicoides species in Portugal in relation to the transmission of African horse sickness and bluetongue viruses. Medical and Veterinary Entomology, 17, 165-177.

Caracappa, S., Torina, A., Guercio, A. etal. (2003) Identification of a novel bluetongue virus vector species of Culicoides in Sicily. Veterinary Record, 153, 71-74.

Carpenter, S., Szmaragd, C., Barber, J., Labuschagne, K., Gubbins, S. \& Mellor, P. (2008) An assessment of Culicoides surveillance techniques in northern Europe: have we underestimated a potential bluetongue virus vector? Journal of Applied Ecology, 45, 1237-1245.

Conte, A., Goffredo, M., Ippoliti, C. \& Meiswinkel, R. (2007) Influence of biotic and abiotic factors on the distribution and abundance of Culicoides imicola and the Obsoletus complex in Italy. Veterinary Parasitology, 150, 333-344.

De Liberato, C., Scavia, G., Lorenzetti, R. et al. (2005) Identification of Culicoides obsoletus (Diptera: Ceratopogonidae) as a vector of bluetongue virus in central Italy. Veterinary Record, 156, 301-304.

De Liberato, C., Farina, F., Magliano, M., Rombolá, P., Scholl, F., Spallucci, V. \& Scaramozzino, P. (2010) Biotic and abiotic factors influencing distribution and abundance of Culicoides obsoletus Group (Diptera: Ceratopogonidae) in central Italy. Journal of Medical Entomology, 47, 313-318.

Dijkstra, E., van der Ven, I.J.K., Hölzel, D.R., van Rijn, P.A. \& Meiswinkel, R. (2008) Culicoides chiopterus as a potential vector of bluetongue virus in Europe. Veterinary Record, 29, 422.

Elbers, A.R.W., Backx, A., Meroc, E., etal. (2008) Field observations during the bluetongue serotype 8 epidemic in 2006. I. Detection of first outbreaks and clinical signs in sheep and cattle in Belgium, France and the Netherlands. Preventive Veterinary Medicine, 87, $21-30$.

Elbers, A.R.W., van der Spek, A.N. \& van Rijn, P.A. (2009) Epidemiologic characteristics of bluetongue virus serotype 8 laboratoryconfirmed outbreaks in the Netherlands in 2007 and a comparison with the situation in 2006. Preventive Veterinary Medicine, 92, 1-8.

Food and Agriculture Organization of the United Nations (FAO), International Institute for Applied Systems Analysis (IIASA), ISRIC-World Soil Information (ISRIC), Institute of Soil Sciences - Chinese Academy of Science (ISS-CAS), Joint Research
Centre of the European Commission (JRC). (2009) Harmonized World Soil Database (Version 1.1). FAO, Rome; IIASA, Laxenburg. http://www.iiasa.ac.at/Research/LUC/External-Worldsoil-database/HTML/ [Accessed 7 May 2013].

Foxi, C. \& Delrio, G. (2010) Larval habitats and seasonal abundance of Culicoides biting midges found in association with sheep in northern Sardinia, Italy. Medical and Veterinary Entomology, 24, 199-209.

Goetz, S.J., Prince, S.D. \& Small, J. (2000) Advances in satellite remote sensing of environmental variables for epidemiological applications. Remote Sensing and Geographical Information Systems in Epidemiology (ed. by S.I. Hay, S.E. Randolph \& D.J. Rogers), pp. 217-243. Academic Press, San Diego, CA.

Goffredo, M. \& Meiswinkel, R. (2004) Entomological surveillance of bluetongue in Italy: methods of capture, catch analysis and identification of Culicoides biting midges. Bluetongue, Part 1 (ed. by N.J. MacLachlan \& J.E. Pearson). Proceedings of the Third International Symposium, Taormina, 26-29 October 2003. Veterinaria Italiana, Vol. 40 (3), 260-265. Istituto Zooprofilattico Sperimentale dell'Abruzzo e del Molise "Giuseppe Caporale", Teramo, Italy.

Guis, H., Caminade, C., Calvete, C., Morse, A.P., Tran, A. \& Baylis, M. (2012) Modelling the effects of past and future climate on the risk of bluetongue emergence in Europe. Journal of the Royal Society, Interface, 9, 339-350.

Harrup, L.E., Purse, B.V., Golding, N., Mellor, P.S. \& Carpenter, S. (2013) Larval development and emergence sites of farm-associated Culicoides in the United Kingdom. Medical and Veterinary Entomology, doi: 10.1111/mve.12006.

Hartemink, N.A., Purse, B.V., Meiswinkel. R. et al . (2009) Mapping the basic reproduction number (R0) for vector-borne diseases: a case study on bluetongue virus. Epidemics, 1, 153-161.

Huete, A., Didan, K., Miura, T., Rodriguez, E.P., Gao, X. \& Ferreira, L.G. (2002) Overview of the radiometric and biophysical performance of the MODIS vegetation indices. Remote Sensing of Environment, 83, 195-213.

Kluiters, G., Sugden, D., Guis, H., McIntyre, K.M., Labuschagne, K., Vilar, M.J. \& Baylis, M. (2013) Modelling the spatial distribution of Culicoides biting midges at the local scale. Journal of Applied Ecology, 50, 232-242.

de Koeijer, A.A., Boender, G.J., Nodelijk, G., Staubach, C., Meroc, E. \& Elbers, A.R.W. (2011) Quantitative analysis of transmission parameters for bluetongue virus serotype 8 in Western Europe in 2006. Veterinary Research, 42, 53.

MacLachlan, N.J. (2010) Global implications of the recent emergence of bluetongue virus in Europe. Veterinary Clinics of North America: Food Animal Practise, 26, 163-171.

Meiswinkel, R., van Rijn, P., Leijs, P. \& Goffredo, M. (2007) Potential new Culicoides vector of bluetongue virus in northern Europe. Veterinary Record, 161, 564-565.

Meiswinkel, R., Scolamacchia, F., Dik, M., Mudde, J., Dijkstra, E., van der Ven, I.J.K. \& Elbers, A.R.W. (2013) The Mondrian matrix: Culicoides abundance and seasonal incidence during the 2006-2008 epidemic of bluetongue in the Netherlands. Medical and Veterinary Entomology, doi: 10.1111/mve.12013.

Meiswinkel, R., Goffredo, M., Leijs, P. \& Conte, A. (2008) The Culicoides 'snapshot': a novel approach used to assess vector densities widely and rapidly during the 2006 outbreak of bluetongue (BT) in the Netherlands. Preventive Veterinary Medicine, 87, 98-118. 
Mellor, P.S., Boorman, J. \& Baylis, M. (2000) Culicoides biting midges: their role as arbovirus vector. Annual Review of Entomology, 45, 307-340.

Olson, D.M., Dinerstein, E., Wikramanayake, E.D., etal. (2001) Terrestrial ecoregions of the world: a new map of life on Earth. BioScience, 51, 933-938.

Peng, R.K., Fletcher, C.R. \& Sutton, S.L. (1992) The effect of microclimate on flying dipterans. International Journal of Biometeorology, 36, 69-76.

Purse, B.V., Baylis, M., Tatem, A.J., et al. (2004a) Predicting the risk of bluetongue through time: climate models of temporal patterns of outbreaks in Israel. Revue Scientifique et Technique de l'Office International des Epizooties, 23, 761-775.

Purse, B.V., Tatem, A.J., Caracappa, S., Rogers, D.J., Mellor, P.S., Baylis, M. \& Torina, A. (2004b) Modelling the distributions of Culicoides bluetongue virus vectors in Sicily in relation to satellitederived climate variables. Medical and Veterinary Entomology, 18, 90-101.

Purse, B.V., Brown, H.E., Harrup, L., Mertens, P.P. \& Rogers, D.J. (2008) Invasion of bluetongue and other orbivirus infections into Europe: the role of biological and climatic processes. Revue Scientifique et Technique de l'Office International des Epizooties, 27, 427-442.

Purse, B.V., Falconer, D., Sullivan, M.J., etal. (2012) Impacts of climate, host and landscape factors on Culicoides species in Scotland. Medical and Veterinary Entomology, 26, 168-177.

R Development Core Team (2009) R: A Language and Environment for Statistical Computing, Version 2.14.0. R Foundation for Statistical Computing, Vienna. http://www.r-project.org [Accessed 7 May year].

Ribeiro, J.R. \& Diggle, P.J. (2001) geoR: a package for geostatistical analysis. $R$-NEWS , 1, 15-18.

Rigot, T., Conte, A., Goffredo, M., Ducheyne, E., Hendrickx, G. \& Gilbert, M. (2012a) Predicting the spatio-temporal distribution of Culicoides imicola in Sardinia using a discrete-time population model. Parasites \& Vectors, 5, 270.

Rigot, T., Vercauteren Drubbel, M., Delecolle, J.C. \& Gilbert, M. (2012b) Farms, pastures and woodlands: the fine-scale distribution of Palaearctic Culicoides spp. biting midges along an agroecological gradient. Medical and Veterinary Entomology, 27, 29-38.

Sanders, C.J., Shortall, C.R., Gubbins, S. et al. (2011), Influence of season and meteorological parameters on flight activity of Culicoides biting midges. Journal of Applied Ecology, 48, 1355-1364.

Savini, G., Goffredo, M., Monaco, F. et al. (2005) Bluetongue virus isolations from midges belonging to the Obsoletus complex (Culicoides, Diptera: Ceratopogonidae) in Italy. Veterinary Record, 157, 133-139.

van Schaik, G., Berends, I.M.G.A., van Langen, H., Elbers, A.R.W. \& Vellema, P. (2008) Seroprevalence of bluetongue serotype 8 in cattle in the Netherlands in spring 2007, and its consequences. Veterinary Record, 163, 441-444.

Silbermayr, K., Hackländer, K., Doscher, C., Koefer, J. \& Fuchs, K. (2011) A spatial assessment of Culicoides spp. distribution and bluetongue disease risk areas in Austria. Berliner und Münchener Tierärztliche Wochenschrift, 124, 228-235.

Sithiprasasna, R., Lee, W.J., Ugsang, D.M. \& Linthicum, K.J. (2005) Identification and characterization of larval and adult anopheline mosquito habitats in the Republic of Korea: potential use of remotely sensed data to estimate mosquito distributions. International Journal of Health Geographics, 4, 4-17.

Tabachnick, W.J. (2010) Challenges in predicting climate and environmental effects on vector-borne disease episystems in a changing world. Journal of Experimental Biology, 213, 946-954.

Takken, W., Verhulst, N., Scholte, E.J., Jacobs, F., Jongema, Y. \& van Lammeren, R. (2008) The phenology and population dynamics of Culicoides spp. in different ecosystems in the Netherlands. Preventive Veterinary Medicine, 87, 41-54.

Tatem, A.J., Baylis, M., Mellor, P.S., Purse, B.V., Capela, R., Pena, I. \& Rogers, D.J. (2003) Prediction of bluetongue vector distribution in Europe and north Africa using satellite imagery. Veterinary Microbiology, 97, 13-29.

Titeux, N., Maes, D., Marmion, M., Luoto, M. \& Heikkinen, R.K. (2009) Inclusion of soil data improves the performance of bioclimatic envelope models for insect species distributions in temperate Europe. Journal of Biogeography, 36, 1459-1473.

van der Veer, G. (2006) Geochemical soil survey of the Netherlands, NGS 347-Atlas of major and trace elements in topsoil and parent material; assessment of natural and anthropogenic enrichment factors. PhD Dissertation, Faculty of Earth Sciences, Utrecht University, Utrecht.

Viennet, E., Garros, C., Lancelot, R., etal. (2011) Assessment of vector/host contact: comparison of animal-baited traps and UVlight/suction trap for collecting Culicoides biting midges (Diptera: Ceratopogonidae), vectors of orbiviruses. Parasites \& Vectors, 4 119.

Viennet, E., Garros, C., Rakotoarivony, I., etal. (2012) Host-seeking activity of bluetongue virus vectors: endo/exophagy and circadian rhythm of Culicoides in western Europe. PLoS One, 7, e48120.

Wan, Z., Zhang, Y., Zhang, Q. \& Li, Z.L. (2002) Validation of the land-surface temperature products retrieved from Terra Moderate Resolution Imaging Spectroradiometer data. Remote Sensing of Environment, 83, 163-180.

Wittman, E.J., Mellor, P.S. \& Baylis, M. (2001) Using climate data to map the potential distribution of Culicoides imicola (Diptera: Ceratopogonidae) in Europe. Revue Scientifique et Technique de l'Office International des Epizooties, 20, 731-740.

Zeileis, A., Kleiber, C. \& Jackman, S. (2008) Regression models for count data in R. Journal of Statistical Software, 27, 1-25. http://www.jstatsoft.org/v27/i08/ [Accessed 7 May 2013].

Zuur, A.F., Ieno, E.N., Walker, N.J., Saveliev, A.A. \& Smith, G.M. (2009) Zero-truncated and zero-inflated model for count data. Mixed Effects Models and Extensions in Ecology with R, Vol. 32, pp. 261-293.

Accepted 14 May 2013

First published online 22 October 2013 